\title{
Eulogio de Córdoba y las reliquias de los mártires
}

\section{Eulogio of Córdoba and the relics of the martyrs}

\author{
ARIEL GUIANCE \\ Consejo Nacional de Investigaciones Científicas \\ aguiance@conicet.gov.ar
}

\begin{abstract}
Resumen: Personaje destacado en el mundo cultural de la Hispania del siglo ix, la obra de Eulogio de Córdoba se impone como la fuente fundamental para conocer el complejo proceso que enfrentó a la comunidad cristiana local con los invasores musulmanes. Tal obra ha sido analizada en numerosas ocasiones, indagando aspectos variados del pensamiento de este autor. En ese sentido, quisiera detenerme brevemente en un asunto menos explorado del discurso de Eulogio como es el que atañe al problema de los restos de los santos (en especial, de aquellos retratados en sus obras) y de la trascendencia que alcanzaron (o no) tales vestigios. En tal sentido, se buscará indagar en la manera en que Eulogio enfoca el problema de la conservación de los cuerpos de esos mártires, problema acuciante en la medida en que las autoridades islámicas tendían a deshacerse de esos cadáveres - considerados, a su juicio, como simples condenados civiles-. De igual manera, se estudiará cómo Eulogio trata de legitimar e imponer el culto que debía brindarse a esas reliquias y, con ello, su deseo de perpetuar la memoria de esos supuestos defensores de la fe cristiana.
\end{abstract}

Palabras clave: Eulogio de Córdoba, martirio, reliquias.

Abstract: Distinguished character in the cultural world of the ninth century Hispania, the works of Eulogio of Córdoba appear as fundamental source to learn about the complicated process that confronted the local Christian community with the Muslim invaders. His works have been analyzed in numerous occasions, exploring different aspects of the author's ideology. In this sense, I would like to shortly consider in a less explored aspect of Eulogio's works, as it's the problem of the Saints' remains (specially, those that appear in his works) and of the transcendence that such relics got (or not). In that sense, I will look to analyze the way that Eulogio focuses on the difficulty that of the preservation of the bodies of these martyrs. This is a recurrent problem in the sense that the Islamic authorities tended to dispose the corpses — that they considered simple civilians. In a similar way, I will develop on how Eulogio tries to legitimize and impose the cult that those relics were supposed to have and his desire to perpetuate the memory of those supposed defenders of the Christian faith.

Keywords: Eulogio of Córdoba, martyrdom, relics.

Revista Historia Autónoma, 11 (2017), pp. 279-297.

e-ISSN: 2254-8726; DOI: https://doi.org/10.15366/rha2017.11.014 
Referente destacado dentro del panorama literario de la Hispania del siglo Ix, la figura de Eulogio de Córdoba se impone como un claro paradigma de la tradición cultural local y de la supervivencia de tal tradición en tiempos de la dominación musulmana. Miembro de una de las tantas familias cristianas que supieron adaptarse a los nuevos tiempos, Eulogio fue educado bajo la tutela de otro representante de la vida intelectual de Al-Ándalus en dicho siglo, el abad Esperaindeo. Junto a este último, también se formó un tercer gran nombre de la literatura de la época, Paulo Álvaro (que se vinculó a Eulogio probablemente desde su juventud, quizás en la misma etapa formativa de ambos). Escritor apasionado, viajero incansable, defensor de la cultura latina y hagiógrafo consumado, el mismo Eulogio alcanzó gran renombre por su defensa del célebre movimiento martirial iniciado hacia mediados de ese siglo ix en la Hispania del sur y que dio lugar a un voluminoso corpus de obras propias. Por todo ello, tal producción y la biografía particular de este autor han sido objeto de múltiples estudios, análisis que van desde el panegírico personal hasta la indagación acerca de la realidad histórica que le tocó vivir (pasando por la consideración de los motivos que lo impulsaron a defender y difundir dicho movimiento martirial) ${ }^{1}$.

En ese vasto campo de posibilidades, quisiera detenerme brevemente en un aspecto menos explorado del pensamiento de Eulogio como es el que atañe al problema de los restos de los santos (en especial, de aquellos retratados en sus obras) y de la trascendencia que alcanzaron (o no) tales vestigios. En efecto, en varias ocasiones ha sido abordada la particular idea que forjó el eclesiástico cordobés acerca del martirio contemporáneo, así como su voluntad de inscribir en la categoría de muertos por la fe a aquellos cristianos ajusticiados por los musulmanes. Otro tanto sucedió respecto a su deseo de imponerlos como santos (por más que las vidas de estos fieles no estuvieran rodeadas de circunstancias maravillosas ni obraran milagros tras su muerte) $)^{2}$. En cambio, menos atención se ha prestado a la manera en que Eulogio enfocó el problema de la conservación de los cuerpos de esos - a su criterio- personajes celestiales. Tal problema resultaba acuciante en la medida en que las autoridades islámicas tendían a deshacerse de esos cadáveres (considerados, a su juicio, como simples condenados civiles). De igual manera -y esto era bien conocido por el autor cordobés-, se imponía la necesidad de legitimar el culto

\footnotetext{
${ }^{1}$ Como es fácil de advertir, resulta imposible reseñar la bibliografía existente acerca de la figura de san Eulogio. Desde el antiguo Pérez de Urbel, Justo, San Eulogio de Córdoba, Madrid, Voluntad, 1928 (claro exponente de la producción histórica y personal de este especialista) hasta los muchos estudios que le han dedicado María Jesús Aldana García y Pedro Herrera Roldán en los últimos tiempos (incluyendo sus respectivas traducciones al español de las obras de Eulogio), la lista es variada y abundante. Un reciente resumen crítico acerca de nuestro autor puede verse en Andrés Sanz, María Adelaida, "Eulogio de Córdoba", en Codoñer, Carmen (ed.), La Hispania visigótica y mozárabe. Dos épocas en su literatura, Salamanca, Universidad de Salamanca, 2010, pp. $277-284$. Cfr., igualmente, Domínguez del Val, Ursicino, Historia de la antigua literatura latina hispano-cristiana. Tomo VI, Madrid, Fundación Universitaria Española, 2004, pp. 99-176.

${ }^{2}$ Buena parte de esos aspectos han sido cuidadosamente analizados en Wolf, Kenneth Baxter, Christian Martyrs in Muslim Spain, Cambridge, Cambridge University Press, 1988; y en Coope, Jessica Ann, The Martyrs of Córdoba. Community and Family Conflict in an Age of Mass Conversion, Lincoln y Londres, Nebraska University Press, 1995 (más enfocado hacia el tema del choque entre identidades musulmanas y cristianas en la Hispania de la época).
} 
que podía brindarse a esas reliquias y, con ello, la perduración de la memoria de esos supuestos defensores de la fe cristiana.

Tal labor fue abordada por Eulogio en varias de sus obras aunque solo en una de ellas (un pasaje específico de su Liber apologeticum martyrum) llevó a cabo una exposición algo más detallada del asunto. Cabe recordar de antemano (y como bien subraya toda la bibliografía relativa a san Eulogio) que el estudio sobre el pensamiento de este prelado parte del inconveniente de que no contamos con manuscritos medievales que transmitan su producción, sino que dependemos de la tradición documental gestionada por el obispo de Palencia, Pedro Ponce de León, y ejecutada por Ambrosio de Morales en el siglo XVI . La situación es aún más complicada si tenemos presente la reiterada actitud de Morales a la hora de dar a conocer las hagiografías hispanas medievales, caracterizada por su permanente intervención en los textos (circunstancia que él mismo admite) $)^{4}$. En este caso, para realizar tal tarea, el editor contó con un manuscrito de las obras de Eulogio (quizás dos, a juzgar por los datos aportados por ambos eclesiásticos ${ }^{5}$ ), texto al parecer conservado en Oviedo desde la segunda mitad del siglo IX y supuestamente transportado a esta ciudad junto con los restos de Eulogio (suceso que habría tenido lugar en 884). Como sea, tal manuscrito (o ambos) se perdieron poco tiempo después, haciendo depender toda la tradición literaria acerca de este autor en función del relato transmitido por Morales. La acotación me parece oportuna ya que intentaremos hacer algunas observaciones en torno a ciertos conceptos invocados por Eulogio acerca de nuestro tema y los vocablos supuestamente empleados por él para definirlos (teniendo que aceptar, de manera implícita, que tales vocablos fueron efectivamente los usados por nuestro autor). La dificultad puede subsanarse parcialmente si cotejamos el empleo de esos conceptos en la obra de otros escritores contemporáneos de Eulogio (empezando por el citado Paulo Álvaro) o bien en la de autores de tiempos visigodos — circunstancia que podría confirmar algunas de estas observaciones-. Más allá de esas salvedades, veamos entonces de qué manera Eulogio transforma en reliquias sagradas los restos de esos fanáticos cristianos que revolucionaron el ambiente social y cultural de Al-Ándalus en plena época del emirato, desatando una de las mayores controversias religiosas de la historia hispana medieval.

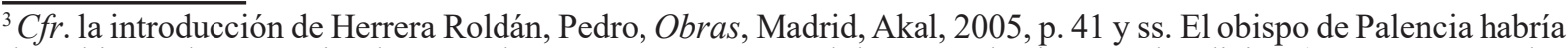
descubierto el manuscrito de estas obras en 1572, encargándole a Morales la tarea de edición (que aparecería dos años después).

${ }^{4}$ Ibídem, p. 42.

${ }^{5}$ Cfr. Mellado Rodríguez, Joaquín, "Eulogius Cordubensis Presb.", en Chiesa, Paolo y Lucia Castaldi (eds.), La trasmissione dei testi latini del Medioevo. Mediaeval Latin Texts and their Transmission. Te.Tra.1, Florencia, Sismel-del Galluzzo, 2004, pp. 118-126. Según Morales, él contaba con un códice hecho copiar por el obispo Pelayo de Oviedo a fines del siglo XI, en tanto Ponce de León señalaba otro datado del siglo IX.
} 


\section{Los cuerpos de los mártires, entre la devoción y el desprecio}

Como acabamos de señalar, uno de los objetivos principales planteados por Eulogio en su obra se basó en la necesidad de demostrar que los personajes por él retratados eran auténticos santos, con todos los atributos propios de tal condición. Para ello, acudió a varias estrategias paralelas: por un lado, buscó "diabolizar al adversario musulmán presentándolo como cruel, libidinoso, soporte del Anticristo Mahoma"6. En segundo término, caracterizó a esos mártires "según las exigencias de los topoi hagiográficos: [escribiendo] vitae y passiones al estilo de aquellas correspondientes a los mártires antiguos"7. Esta voluntad de equiparación fue una constante en el pensamiento de nuestro autor, quien insistió en que los mártires contemporáneos no se diferenciaban en nada a los del pasado. Así, en uno de los primeros pasajes de su Memoriale sanctorum (una obra compuesta entre 851 y $856^{8}$ ) exclamó:

\footnotetext{
"me he esforzado por enfrentarme no solo a quienes no quieren admitirlos [i.e., a sus biografiados] como mártires, sino que también los atacan con boca sacrílega con reproches y blasfemias y provocan, si es posible, un renovado suplicio al descanso eterno de los santos" .
}

Esa voluntad de exaltación lo llevó a subrayar que tales muertes habían sido dignas a los ojos del Señor y que esos mismos cristianos fueron quienes persiguieron deliberadamente ese fin: "desean perecer, según el apóstol, y estar con Cristo, pues buscan un atajo por medio del cual, arrancados del cuerpo de esta vida mortal, llegar rápidamente a la patria celestial y apoderarse con piadosa violencia del reino de Dios" ${ }^{\prime 10}$. Ese cuerpo mortal, por tanto, no representaba más que un estorbo para alcanzar tales propósitos y el mártir debía desembarazarse de él para acceder al reino celestial.

Aceptada, pues, esa muerte martirial, la actitud que demostró Eulogio en esta obra respecto de los cadáveres de esos personajes es doble y, en ocasiones, hasta contradictoria. En efecto, en primer lugar el escritor cordobés subrayó que los restos de esos ajusticiados se

\footnotetext{
${ }^{6}$ Tolan, John, "Reliques et païens: la naturalisation des martyrs de Cordoue à Saint-Germain (IXe siècle)", en Sénac, Philipe (ed.), Aquitaine-Espagne (VIIIe-XIIIe siècle), Poitiers, Universidad de Poitiers, 2001, p. 41.

${ }^{7}$ Ibídem, p. 42.

${ }^{8}$ Para la cronología de las obras de Eulogio, véase Flórez, Enrique, España sagrada. Tomo X, Madrid, Imprenta de José Rodríguez, 1792, p. 440 y ss. Cfr. Andrés Sanz, María Adelaida, "Eulogio de Córdoba...” op. cit., p. 280. ${ }^{9}$ Eulogio, Memoriale sanctorum, I, \& 2 (sigo la edición de Gil, Juan, Corpus scriptorum muzarabicorum. Tomo II, Madrid, Consejo Superior de Investigaciones Científicas, 1973, p. 370): “[...] qui non solum eos recipere inter martyres nolunt, uerum etiam ore sacrilego conuiciis atque blasphemiis impetentes rediuiuum, si possibile est, quieti [s] sanctorum implodunt supplicium". En adelante, se citará con número romano el libro correspondiente de cada obra, en arábigo el capítulo y, antecedido del signo \&, el párrafo (si lo hubiere). Para una consideración amplia acerca del tema del martirio en la prosa de Eulogio, véase Wolf, Kenneth, Christian Martyrs... op. cit., pp. 62-74. Las traducciones de los textos de Eulogio corresponden, con leves variantes, a la edición de Aldana García, María Jesús, Obras completas de san Eulogio: introducción, traducción y notas, Córdoba, Universidad de Córdoba, 1998.

${ }^{10}$ Ibídem, I, \& 6, p. 374: "temporalis uitae accenduntur et secundum apostolum dissolui cupiunt et esse cum Xpo, uiam compendii requirentes qua de corpore mortis huius eruti propere ad caelestem patriam peruenirent et pia uiolentia regnum Dei arriperent".
} 
convirtieron desde un principio en auténticas reliquias cristianas — con todas las constantes hagiográficas que ello suponía- y que la presencia de tales restos sirvió para acrecentar la devoción y difusión de la figura de estos mártires. Así, los cadáveres de Nunilo y Alodia dos jóvenes oscenses-, arrojados a un foso por los sarracenos, “[...] en el lugar en el que los paganos los habían escondido, más que enterrado [...], resplandecían con signos y milagros $y$, con la eficiencia de sus poderes, les mostraban tanto a los fieles como a los gentiles, la gloria de su merecido consuelo" ". Por lo mismo, desde un comienzo se planteó la voluntad de obtener esas reliquias, pese a todas las adversidades. La gracia de Dios, por ejemplo, obró para recuperar parte de los restos de Emila y Jeremías, cuyas cenizas "con el auxilio divino, fueron guardadas en los santos lugares"12. Esa ayuda providencial hace que Eulogio declarase: "joh admirable poder del Salvador y asombrosa virtud de Nuestro Señor Jesucristo, quien siempre nos asiste en la desgracia, si lo buscamos [...]!"”13.

Ahora bien, al mismo tiempo que se inclina hacia el sentido anterior, Eulogio sugirió que los santos de su tiempo no necesitaban de tal culto de sus reliquias para ser considerados como tales (y que, aun sin contar con esos restos, ellos merecían la devoción correspondiente). Con esta última salvedad, el eclesiástico intentó superar el hecho de que muchos de esos mártires fueron particularmente escarnecidos por los musulmanes a fin de evitar que "ningún cristiano, movido por la piedad, sepultase esos cadáveres, despojados incluso de sus carnes"14. A juicio de Eulogio, los propios musulmanes eran conscientes del posible valor de esos cuerpos y, en algunas ocasiones, "para que no proporcionaran a los cristianos una ganancia de virtudes, sepultaron en el profundo abismo del río amenazante las deformes cenizas que habían podido apartar de la hoguera" 15 — refiriéndose al caso de san Perfecto—. Esta situación, según el mismo escritor, no significaba nada para los propios santos ya que ello no impedía que esos elegidos disfrutasen de la gloria celestial aunque se los sepultase "entre ignominias". En suma, según el mismo Eulogio, los cuerpos de los mártires cordobeses constituían auténticas reliquias cristianas pero la imposibilidad de contar con ellos no alteraba en lo más mínimo la devoción que se debía a esos (a su criterio) santos consagrados, tal como sucedía respecto de cualquier otro ser celestial.

La segunda reflexión de Eulogio que figura en el Memoriale sanctorum en torno a este tema de las reliquias se enfocó hacia un problema mucho más importante. Se trata de la acusación formulada por quienes creían que, como los cuerpos de esos personajes eran objeto de corrupción - a diferencia de lo que supuestamente ocurría con los auténticos santos, ajenos

\footnotetext{
${ }^{11}$ Ibidem, II, 7, p. 408: “[...] in loco, quod ab ethnicis altis scrobibus magis abscondita quam humata sunt, signis et miraculis coruscant et gloriam emeritae consolationis uirtutum efficientia tam fidelibus quam gentilibus ostentant $[\ldots]^{\prime \prime}$.

${ }_{12}^{2}$ Ibídem, II, 16, p. 436: "quorum cineres Deo fautore per loca sancta repositi sunt".

${ }^{13}$ Ibidem: "o admiranda potentia Saluatoris et stupenda uirtus Domini nostri Iesu Xpi, qui semper quaesitus in tribulatione assistit, pulsatus aperit, inuocatus exaudit!".

${ }^{14}$ Ibidem I, 17, p. 382: "[...] ne quis catholicorum intuitu pietatis carnibus etiam spoliata cadauera sepeliret".

${ }^{15}$ Ibidem, I, 11, p. 378: "quin etiam ne uirtutum emolumenta praestarent Xpicolis, deformes cineres quos legere a camino quiuerant minacis aluei ultimo conduntur abysso".
} 
a la putrefacción de la carne-, ellos no merecían ser reconocidos como tales. Para rebatir esa idea, nuestro autor se preguntó:

\begin{abstract}
“¿por qué se iban a inquietar con una vana preocupación sobre la integridad de los cuerpos quienes sabían que toda la salvación temporal iba a desaparecer también con el propio mundo y que aquella sentencia de muerte dada a Adán, el primer hombre, «Polvo eres y en polvo te convertirás» (Gen. III, 10) atañe a todos los mortales en general?"16.
\end{abstract}

En otras palabras, los santos - como cualquier cristiano- sabían que sus cuerpos no tenían valor y que todos habrán de gozar de la resurrección el día del Juicio final. Esa afirmación era tan universal que "cuando el profeta dijo «toda» no dejó atrás ninguna carne nacida de semilla humana y, aunque de manera osada, diré que tampoco la de los patriarcas, ni la de los profetas, ni la de los apóstoles, ni la de los mártires" ${ }^{17}$. De tal modo —y apelando a ejemplos bíblicos tales como los de David, Job y Lázaro-, nuestro autor buscó diluir el tema en el hecho de que esa desintegración de la carne era propia de todos los seres humanos, más allá de su condición. Sin dar una respuesta concreta al asunto, Eulogio se limitó a descalificar la mencionada impugnación, concluyendo que "esta corrupción temporal y pasajera" en nada afectaba las almas de los santos, quienes debían ser admitidos como seres celestiales, sin importar las posibles señales de corrupción material. Ahora bien, pese a esta afirmación, el mismo Eulogio - como ocurriera en el caso anterior - también adoptó una actitud diferente en este sentido. En efecto (tal y como luego veremos), siempre que pudo demostró que sus biografiados gozaron de determinadas gracias sobrenaturales, que permitieron (entre otras cosas) que sus cuerpos no se desintegraran, permanecieran inalterados y hasta despidiesen perfumes agradables muchos días después de fallecidos.

Conforme a esas dicotomías, el escritor cordobés distinguió claramente en sus obras entre dos modelos de veneración martirial, según se contara o no con reliquias de esos santos y, de manera subsidiaria, si existieran o no elementos de carácter celestial que verificaran la validez de tales reliquias. Así, por un lado enumeró aquellos restos de los mártires andaluces que pudieron ser recuperados tras sus suplicios y convertirse rápidamente en objetos de culto. En segundo término, en cambio, señaló los casos en que tales restos fueron convenientemente destruidos u ocultados por las autoridades musulmanas. Un ejemplo paradigmático del primer grupo es el del citado san Perfecto (muerto en 850 e iniciador de esta oleada martirial). Decapitado tras una larga agonía, "el cuerpo del santo mártir recibió sepultura, entre los piadosos oficios de los religiosos y el digno honor del obispo y de los clérigos, en la basílica de San Acisclo,

\footnotetext{
${ }^{16}$ Ibidem, I, 26, p. 389: "Nam cur uana sollicitudine de corporum integritate distenderentur, qui uere nouerant omnem temporalem salutem etiam cum ipso mundo perire et illam protoplasto Adae sententiam mortis collatam generaliter cunctis mortalibus congruere: «Puluis es, et puluerem reuerteris»".

${ }^{17}$ Ibídem: "Et cum omnem dicit, nullius carnem ex humano semine orientem reliquit, et licet audacter, dicam tamen, non patriarcharum, non prophetarum, non apostolorum, non martyrum".
} 
en la que descansan sus felices miembros" ${ }^{18}$. Como es fácilmente apreciable, la voluntad de Eulogio, en esta oportunidad, radicó en demostrar que ese primer martirio no fue confrontado por la jerarquía eclesiástica local (cuyo obispo, Saulo ${ }^{19}$, acompañó solemnemente el cadáver de Perfecto hasta su tumba, depositando sus despojos en un ámbito sagrado y junto a las reliquias de uno de los mártires más venerados de la Córdoba del siglo IX, Acisclo). Ahora bien, a medida que avanzó el movimiento martirial, esas inhumaciones no tuvieron el mismo carácter público y ceremonial sino que se hicieron en secreto y en contra de la voluntad del poder musulmán. No obstante, se trata igualmente de restos recuperados y posibles objetos de devoción. Así, el cuerpo del diácono Sisenando (muerto en junio de 851) fue hallado "gracias a un don de Dios (donante Deo)" por unas mujeres en la grava del río Guadalquivir y traslado a la mencionada iglesia de San Acisclo ${ }^{20}$. Por su parte, los de Pablo y Teodomiro (ejecutados el mismo año) fueron robados de la entrada del palacio del emir por unos cristianos valerosos y llevados a la iglesia de San Zoilo ${ }^{21}$, mientras que los de Gumersindo y Servideo (m. 852) fueron igualmente hurtados por ciertos fieles y transportados a la basílica de San Cristóbal mártir, donde fueron "guardados con religioso culto"22. Otro tanto puede decirse de los cuerpos de Cristóbal y Leovigildo (recuperados de la hoguera "antes de que se consumiesen totalmente" e inhumados en la citada basílica de San Zoilo ${ }^{23}$ ) y los referidos de Emila y Jeremías. Similar situación se verifica, finalmente, respecto del grupo de mártires formado por Jorge, Aurelio, Natalia (o Sabigoto, como también será conocida), Liliosa y Félix (particularmente detallado por Eulogio ya que tuvo contacto con la mayor parte de ellos). En este caso, el hagiógrafo señala el sitio exacto donde fueron a parar los despojos de estos personajes: Jorge y Aurelio fueron inhumados en el monasterio de Peñamelaria, Félix en la iglesia de San Cristóbal, Natalia en la basílica de los Tres Santos (esto es, la consagrada a Fausto, Genaro y Marcial) y Liliosa en la de San Ginés $^{24}$. Curiosa es la frase inconclusa que cierra el párrafo consagrado a estos mártires ya que, tras esa cuidadosa enumeración, Eulogio expresa que "las cabezas de Jorge y Sabigoto se encuentran..." (Capita vero Georgii et Sabigothonis incolunt...), quedando incompleta su oración (al menos, tal como aparece en la versión conocida de esta obra). Dejemos de lado, por el momento, la posible razón de esta salvedad (sobre la cual volveremos ya que atañe a un documentado traslado de reliquias ocurrido en 858 , apenas unos años después de la muerte de estos últimos mártires).

\footnotetext{
${ }^{18}$ Ibidem, II, 1, \& 5, p. 400: "Corpus autem sancti martyris piis religiosorum officiis dignoque praesulis et sacerdotum obsequio in basilica beati Aciscli in eo titulo, quo felicia eius membra quiescunt, humatur".

${ }^{19}$ Para la figura de Saulo - "uno de los más tenaces defensores de los controvertidos mártires voluntarios" véase Paniagua, David, "Saulo de Córdoba", en Codoñer, Carmen (coord.), La Hispania visigótica ... op . cit., pp. 290-293; y Domínguez del Val, Ursicino, Historia de la antigua ... op. cit., pp. 452-457.

${ }^{20}$ Memoriale sanctorum ... op. cit., II, 5, p. 405. Un panorama general acerca de la suerte que tuvieron los distintos cadáveres de estos mártires puede verse en Jiménez Pedrajas, Rafael, "Las relaciones entre los cristianos y los musulmanes en Córdoba", en Boletín de la Real Academia de Córdoba de Ciencias, Bellas Letras y Nobles Artes, 80 (1960), pp. 107-234 (en particular, pp. 203-211).

${ }^{21}$ Memoriale sanctorum ... op. cit., II, 6, pp. 405-406.

${ }^{22}$ Ibídem, II, 9, p. 415.

${ }^{23}$ Ibidem, II, 11, p. 432.

${ }^{24}$ Ibídem, II, 10, \& 34, p. 430.
} 
Como apuntamos antes, en algunas ocasiones la conservación de esos restos dependía de factores sobrenaturales (lo que implícitamente actuaba como garantía del valor celestial de esas reliquias). Esto es lo que sucedió con los cuerpos de las hermanas Nunilo y Alodia, ya citadas. En este sentido, Eulogio subraya que, tras su ajusticiamiento, los despojos de estas mujeres fueron dejados en el sitio de su suplicio al cuidado de "unos soldados para que los cristianos no los robaran furtivamente y les diesen sepultura para ganar su protección" 25 — hecho que no impidió que el lugar se revelara como centro milagroso-. De igual manera, el cadáver de santa Columba se recuperó en virtud de la intervención celestial: “después de seis días, gracias a la providencia divina, su cuerpo nos lo trajo ileso e íntegro la diligencia de unos monjes y, con digno oficio religioso, mereció una honorable sepultura en la basílica de la virgen y mártir santa Eulalia, que está ubicada en la aldea de Fragelas"26. En cambio, al monasterio de Cuteclara fueron destinadas las reliquias de María (decapitada junto a su hermana, Flora), conseguidas en virtud de otro "don de Dios"27 — agregándose expresamente que el cadáver de Flora nunca se halló-. En este último caso, las cabezas cortadas tuvieron un destino diferente, ya que ambas terminaron en la basílica de san Acisclo, desde donde protegen "a los pueblos cristianos con el amparo de su cuerpo presente" 28 .

Frente a ese conjunto de cuerpos recuperados (ya sea por vías humanas o sobrenaturales) y debidamente inhumados se cuenta un segundo contingente de mártires cuyos restos se perdieron para siempre. Cabe advertir que esta situación responde de manera más coherente a la perspectiva musulmana respecto de esta corriente martirial (entendida, según anticipamos, como un acto de provocación y blasfemia cristiana). Así, por ejemplo, Eulogio señala que los despojos de san Isaac — junto a los de otros monjes compañeros de su martirio- fueron incinerados y arrojados al Guadalquivir ${ }^{29}$. Tal situación se repite respecto del contingente integrado por Pedro, Walabonso, Sabiniano, Wistremundo, Habencio y Jeremías ${ }^{30}$, santa Benilde ${ }^{31}$, Elías y los monjes Pablo e Isidoro ${ }^{32}$, Áurea (perdida para siempre en las aguas del mismo río) ${ }^{33}$ y el cuerpo de Flora -dado que su cabeza, como vimos, sí pudo conservarse- En todos los casos, esa pérdida era interpretada por nuestro autor como un claro intento del poder musulmán por evitar que esos restos se convirtieran en objetos de veneración.

El segundo par discursivo considerado por Eulogio es, como señalamos, el que opone restos con poderes milagrosos y aquellos que no manifiestan tales poderes (refiriéndonos, claro

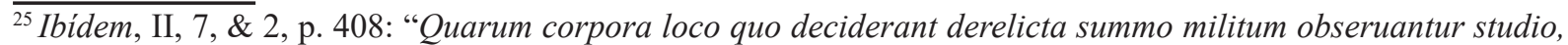
ne Christiani ad emolumentum patrocinationus furtium eas surriperent et reconderent".

${ }^{26}$ Ibídem, III, 10, p. 452: "Quod post sextum diem illaesum et integrum quorundam solertia monachorum diuinitus nobis allatum est dignoque officio in basilica sancta Eulaliae uirginis et martyris, quae in uico Flagellas constituta est $[\ldots] "$ ".

${ }^{27}$ Ibidem, II, 8, p. 415.

${ }^{28}$ Ibídem: "Capita uero illarum in basilica sancti Aciscli martyris reconduntur, quo praesentiali corporis sui fauore populos Xpianos tuetur".

${ }^{29}$ Ibídem, I, prólogo, \& 3, p. 368.

${ }^{30}$ Ibídem, II, 4, p. 404.

${ }^{31}$ Ibídem, III, 9, p. 447.

${ }^{32}$ Ibídem, III, 15, p. 445.

${ }^{33}$ Ibídem, III, 17, p. 459.
} 
está, solo a los cuerpos de los mártires preservados). En este sentido, la dicotomía es una mera derivación de la anterior y resulta muy restringida. En efecto, apenas se indicó que esa capacidad milagrosa se manifiesta (además del caso de Nunilo y Alodia) respecto del grupo conformado por Emila, Jeremías, Rogelio y Servideo. Fue la contemplación de los despojos de estos últimos (clavados en estacas del otro lado del río) lo que provocó que el emir Abd-al-Rahman II quedara mudo de improviso y muriera esa misma noche "antes de que la pira de los santos cadáveres se extinguiese" ${ }^{34}$. Otro tanto podría decirse de santa Columba, de quien se había señalado el hecho de que su cuerpo fue arrojado al Guadalquivir y recuperado seis días después "ileso e íntegro" (illaesum et integrum). Por el contrario, en el resto de los ejemplos retratados en su Memoriale sanctorum, Eulogio nada apuntó de manera específica al respecto, volviendo a diluir el tema en esas alusiones más bien vagas acerca de la intervención de Dios, destinada a permitir la conservación de los cuerpos de los mártires pero sin señalar portento alguno obrado por tales reliquias.

Tras esta exposición acerca del tema, Eulogio volvió sobre el asunto de los restos sagrados en una obra posterior, el Liber apologeticum martyrum (redactado en 857). En él, apareció un discurso más detallado en torno al problema que nos ocupa, discurso nuevamente relacionado con la necesidad de responder a las acusaciones formuladas en el sentido de que esos cristianos cordobeses solo eran rebeldes que impugnaron el poder musulmán (y no debían ser considerados mártires). A tal fin, relató el caso de santos Rodrigo y Salomón. Una vez consumado el ajusticiamiento de estos dos personajes, el hagiógrafo señala haber ido, junto a muchos fieles, a contemplar sus cadáveres, colocados a orillas del Guadalquivir. En esas instancias, Eulogio volvió al tema de la incorruptibilidad de esos restos al señalar "no miento al decir que aquellos cadáveres decapitados brillaban con una hermosura tan excelsa, que se podía creer que iban a hablar de inmediato si alguien les preguntaba" ${ }^{35}$. Tras ello, agregó que los musulmanes decidieron entonces tomar los guijarros manchados con la sangre de los mártires y, tras lavarlos, arrojarlos al río, "para que no los tuvieran los cristianos como una ganancia de reliquias (lipsanorum)" —-desconociendo que "en nada perjudicaba quitarles una parte a esos mártires" ya que las auténticas reliquias habían sido sus vidas y muertes ${ }^{36}$ - . De tal manera, nuestro autor al parecer empleó — por única vez a lo largo de toda su producción- un helenismo (lipsana) para dar cuenta de esos vestigios ${ }^{37}$. El vocablo es curioso ya que no tiene demasiados referentes identificables en la producción hispana (no es usual entre los autores visigodos ni en las passiones de los mártires locales). ¿Se trata de un término efectivamente

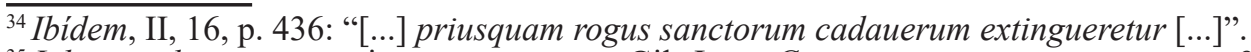

${ }^{35}$ Liber apologeticum - sigo nuevamente a Gil, Juan, Corpus scriptorum ... op. cit. —, \& 31, p. 492: "[...] quod tanta decoris pulchritudine decissa illa cadauera fulgebant, ut crederes, si a quoquam sciscitarentur, protinus locutura".

${ }^{36}$ Ibídem, \& 32: "[...] sumebant lapillos fluminis, qui cruore martyrum erant aspersi, et lymphis abluentes proiciebant in pelago, ne christianis in emolumentum existerent lipsanorum, nescientes quod nihil obesset ab his partem adimere, quibus totam decreuerat Dominus passionem donare".

${ }^{37}$ Cfr. Herrera Roldán, Pedro, Léxico de la obra de san Eulogio, Córdoba, Universidad de Córdoba, 1997, p. 184.
} 
usado por Eulogio? Resulta imposible contestar de manera contundente esta pregunta pero todo hace pensar que ello podría representar, efectivamente, una muestra de ese "desmesurado apego" manifestado por nuestro autor hacia los moldes clásicos ${ }^{38}$ y su rechazo de la lengua vulgar. Cabe recordar, asimismo, que Eulogio apeló muchas veces a esos helenismos "en dos puntos [en los que revela] mayor interés: el martirio y el ascetismo, campos al que pertenecen agon, agonista [...] brabium, martyrizo, palestra [...]"39. Por ende, no sería extraño que, en la misma lógica, el eclesiástico cordobés empleara un vocablo de tal origen para referirse a las reliquias de sus mártires.

Más allá de todo eso, el relato de Eulogio continuó señalando que, tras haber sido finalmente arrojados al Guadalquivir, las propias aguas del río devolvieron los restos de san Rodrigo de las profundidades pese a que estos habían sido atados por los verdugos con pesadas piedras. Otro tanto ocurrió con su cabeza, hallada en las proximidades. Tras veinte días ocultos, unos musulmanes dieron a conocer el paradero de esos restos a un presbítero cristiano, quien los encontró en el lugar donde luego se levantó el monasterio de San Ginés. En esas instancias, Eulogio introdujo otra prueba de la devoción que, a su juicio, rápidamente motivaron esas reliquias (y, junto a ello, de la participación del mencionado obispo cordobés Saulo a favor del movimiento martirial). Según la narración, el traslado de esos restos se hizo de noche, en medio de una procesión iluminada por tantas antorchas, que daban la impresión de señalar "el surgimiento de un día resucitado" ${ }^{40}$. Fue el mismo obispo Saulo quien acarició "con sus besos" ${ }^{41}$ tales reliquias, frase que supone una de las cinco ocasiones en que la prosa de Eulogio empleó precisamente tal término ${ }^{42}$. En este caso, la exposición de nuestro autor guarda una estrecha correspondencia con otro texto, una inventio de un mártir cordobés de la Antigüedad, san Zoilo, relato cuya versión conocida tiene que haberse redactado entre mediados del siglo VIII y principios del XI — fecha que corresponde a su incorporación al llamado Pasionario de Cardena, única compilación que nos ha transmitido tal inventio ${ }^{43}$ - Como ocurriera con san Rodrigo, los huesos de san Zoilo también fueron besados por el obispo Agapio (quien, como consecuencia de ello, perdió sus dientes incisivos superiores). Junto a esto, debe subrayarse el hecho de que Eulogio volvió a usar la voz "reliquias" en una carta que escribió al obispo Wiliesindo de Pamplona — carta que veremos en detalle más adelante-, en la que señaló que este último le había solicitado le enviara "reliquias del santo mártir san Zoilo para dar

\footnotetext{
${ }^{38}$ Ibídem, p. VII.

${ }^{39}$ Ibídem, p. XV.

${ }^{40}$ Liber apologeticum ... op. cit., \& 33, p. 493: “adeo ut nimio splendore omnia illustrante rediuiuum ostentauerit nox illa diem emergere".

${ }^{41}$ Ibídem, \& 34 : "Qui mox sanctas reliquias adeunt et inclitus papa caput [de san Rodrigo] detegit et osculis sancta membra demulcet".

${ }^{42}$ Cfr. Herrera Roldán, Pedro, Léxico de la obra... op. cit., p. 280.

${ }^{43}$ Cfr. de Gaiffier, Baudoin, "L'inventio et translatio de s. Zoïle de Cordoue", en Analecta bollandiana, 56 (1938), pp. 361-369. El texto fue editado por Riesco Chueca, Pilar, Pasionario hispánico, Sevilla, Universidad de Sevilla, 1995 , pp. 244-248.
} 
lustre a los pueblos pamploneses" ${ }^{44}$ — pedido que, como también veremos, fue cumplido satisfactoriamente- Por consiguiente, no sería extraño que Eulogio conociera el relato de esa inventio y aplicara el vocabulario de esta última y parte de sus recursos discursivos para aludir a sus mártires contemporáneos.

En el caso de san Rodrigo, el carácter de restos sagrados se confirmó, según el mismo hagiógrafo, por dos hechos. El primero, el olor agradable que de inmediato comenzaron a desprender sus reliquias, perfume que impregnó el ámbito donde ellas se colocaron ("exhaló un olor de maravillosa suavidad y cuentan que, después de quitar la tierra, todo el pavimento de la celda [donde se depositó el cuerpo del mártir] expelió un aroma de dulcísima fragancia durante algún tiempo" ${ }^{45}$ ). Se trata de un recurso tradicional en la literatura hagiográfica relativa a nuestro asunto, también presente desde los inicios del género ${ }^{46}$. En todos los casos, esos aromas actúan como signo indudable de que los restos en cuestión pertenecían a un ser venerado, en la medida en que compartían con la divinidad su propia esencia perfumada (situación que, además, se extrapolaba en las representaciones medievales del paraíso como un espacio de olor agradable). En segundo término, reaparece el tema de la incorruptibilidad del cadáver como una prueba adicional de la dimensión sobrenatural de las reliquias:
"aconteció, ante el estupor de todos, que ninguna podredumbre había consumido su cadáver sin enterrar, ninguna peste lo había ensuciado, ninguna descomposición lo había corrompido, no lo había despedazado ninguna feroz hambre de fieras o de aves, ni se había deteriorado y alterado la naturaleza de su propia piel" ${ }^{\prime 47}$.

Como en ejemplos anteriores, se trata de otra muestra de que ese ser ha superado la condición normal del resto de los humanos: su cuerpo no sufría la suerte propia de la naturaleza y no despedía los malos olores derivados de la descomposición.

Hallados los restos de san Rodrigo, los fieles se desesperaron por encontrar el cuerpo de su compañero de martirio, el citado Salomón. De este se decía que había sido llevado por la corriente del río hasta el mar. Esta posibilidad "había contenido más el previsor atrevimiento de los cristianos que la furiosa conjura del gobernador, quien había prometido castigar con leyes más severas a quien buscara las reliquias (reliquiarum) del mártir"48 — con una tercera

\footnotetext{
${ }^{44}$ Epistola III ad Wiliesindum episcopum Pampilonensem, \& 5, en Gil, Juan, Corpus scriptorum ... op. cit., p. 499: "Ita de nostra caritate confisus rogas ut Cordubam repetens ipse reliquias tibi sancti martyris Zoyli digerem, et hoc munere Pampilonenses populos illustrarem".

${ }^{45}$ Liber apologeticum, \& 34, p. 493: "redolent secreta cubiculi, quos prius beatum corpus sacerdos intulerat, mito suavitatis odore cunctaque cellulae pauimenta etiam ablato puluere ferunt aliquandiu suauissimi odoris olfactu respirasse".

${ }^{46} \mathrm{Me}$ he ocupado del asunto en Guiance, Ariel, "En olor de santidad. La caracterización y alcance de los aromas en la hagiografía hispana medieval”, en Edad Media. Revista de historia, 10 (2009), pp. 131-161 (al cual me permito remitir).

${ }^{47}$ Liber apologeticum, \& 34, p. 493: "Fit omnibus in stuporem quod inhumatum corpus nulla putredo insumpserit, nulla peste infecerit, nulla tabes corruperit, nulla bestiarum altiliumue rabida fames discerpserit, nec propiae cutis qualitatem tot dierum interiecta capedo degenerans immutauerit".

${ }^{48}$ Ibídem, \& 35, p. 494: "Nam haec opinio prouidum magis christocolarum ausum inhibuerat quam furens conspiratio praesidis, quae acrioribus ulciscendum legibus exploratorem reliquiarum promiserat".
} 
aparición del vocablo- . No obstante ello, ese desconocimiento volvió a superarse (como era de esperar) a través de una revelación que recibió el mismo sacerdote que supo de las reliquias de san Rodrigo. En este caso, es el propio Salomón quien le hace saber el sitio exacto en donde podía hallar su cuerpo: "en aquella orilla del río que está junto al arrabal de la Ninfa, donde me habían arrojado los viandantes entre unos sotos de tamariscos, [encontrarás] mi vil sepultura, cubierta de tierra cenagosa"49. Como se puede apreciar, Eulogio trató de brindar una descripción detallada del lugar, otorgando más credibilidad a su relato. La narración concluye, claro está, con el hallazgo de los restos de Salomón ("no de forma distinta a cómo se había mostrado en la revelación" ${ }^{50}$ ) y su posterior traslado a la iglesia de Santos Cosme y Damián, "del arrabal de la Culebra".

En suma, todo apunta (según anticipamos) a demostrar el valor que tenían los restos de esos mártires contemporáneos y el hecho de que ellos debían ser objeto de veneración (al menos, a juicio de Eulogio). Para conseguir ese propósito, este no dudó en apelar a las tradicionales características hagiográficas propias del tema de las reliquias, repitiendo lo que consignaban las pasiones antiguas: olores perfumados que estas despedían, la incorruptibilidad de las mismas, su preservación en virtud de recursos sobrenaturales (bestias que no osaban tocarlas, cursos de agua que permitían que salieran a la superficie) y su hallazgo, en algunos casos, por similares medios divinos (apariciones que dan cuentan del lugar donde podía encontrárselas, viajes por el río que vuelven a llevarlas a su punto de partida o hasta sitios identificables).

\section{Eulogio como agente de una translatio}

Igual que Eulogio se ocupó por exaltar la dimensión que debía asignarse a esos mártires de su tiempo, también hizo lo propio para dignificar la figura de los mártires cordobeses del pasado. En tal sentido, su labor no se volcó a la redacción de textos laudatorios de esos personajes históricos o legendarios sino que, más bien, participó en auténticos traslados de restos sagrados hacia otras regiones de la cristiandad. Prueba de ello es la mencionada carta que dirige al obispo de Pamplona, Wiliesindo, datada del 15 de noviembre de 851, en la cual hace referencia a ese tema ${ }^{51}$. En ella, el cordobés alude a su viaje al norte peninsular (que tuvo

\footnotetext{
$\overline{{ }^{49} \text { Ibidem: "In illa }}$, inquit, ripa fluminis, quae uico Nymphiano adsciscitur, ibi a commeantibus inter frutecta tamaricum proiectus, caespitis limosi perfruor uili sepulcro".

${ }^{50}$ Ibidem: "nec aliter quam quod ei reuelatione ostensum est repperit".

${ }^{51}$ Para este prelado, véase Goñi, José, "Wiliesindo", en Aldea Vaquero, Quintín et al., Diccionario de historia eclesiástica de España. Suplemento, Madrid, Consejo Superior de Investigaciones Científicas, 1987, p. 704 —que supone su episcopado entre 845 y 860 - . La autenticidad de esa carta ha sido discutida (y confirmada) por Yaben, Hilario, "La autenticidad de la carta de san Eulogio al obispo de Pamplona", en Príncipe de Viana, 5 (1944), pp. $161-172$
} 
lugar hacia 848), en búsqueda del paradero de sus hermanos comerciantes y con la voluntad adicional de obtener copias de libros que se requerían en su ciudad natal. Como ya señalamos, durante su estadía en Pamplona, el citado Wiliesindo habría pedido a Eulogio parte de las reliquias de san Zoilo (o quizás alguna reliquia representativa del mismo santo). La demanda nos pone frente a una práctica que debía ser común entre la alta jerarquía eclesiástica del siglo Ix hispano (y no solo de estos tiempos): la fragmentación y reparto de reliquias entre diversas diócesis. De hecho, Eulogio no manifestó en momento alguno su rechazo a este pedido al que, por lo demás, entiende como loable para difundir el mensaje cristiano y engrandecer la gloria de ciertas sedes-. Si se tratara de restos primarios (esto es, parte del cuerpo del mismo santo), esta situación contrasta con criterios antiguos que establecían la intangibilidad de los despojos de los elegidos de Dios y contradice una serie de normas dictadas en tal sentido entre los siglos IV y VII ${ }^{52}$. Sin embargo, debemos tener en cuenta que ese principio "cayó poco a poco en desuso" a partir de los siglos VIII y $\mathrm{IX}^{53}$, planteándose numerosas excepciones al respecto pese a las reticencias expresadas por los papas hasta, al menos, tiempos de Pascual I (817-824). En el caso de reliquias representativas (objetos que fueron tocados por el santo durante su vida o que rozaron su tumba tras su muerte), la situación no suponía problema alguno. Desafortunadamente, nada nos dice Eulogio acerca de lo que él envió a Wiliesindo. Solo sabemos que el pedido se concretó tras cierta demora, ocasionada por la situación por la que atravesaba la ciudad de Córdoba en esos años: "no he tributado la servidumbre debida a vuestra bondad [dice Eulogio] ni he dado satisfacción a tu piadoso anhelo con el envío de las reliquias, ni he considerado aceptable confiar a cualquiera semejantes y tan grandes riquezas" 54 . Esa situación se destrabó de improviso, gracias a la intervención de un noble cristiano:

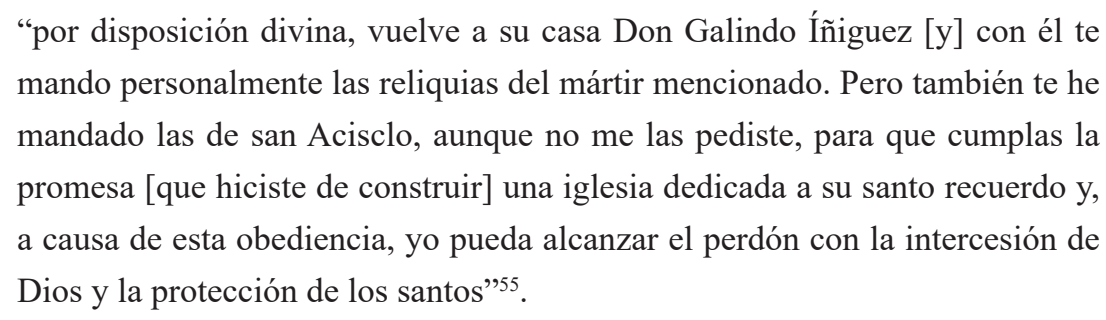

Por lo pronto, el eclesiástico volvió a utilizar la voz reliquias para referirse a los restos en cuestión (consignando sus dos restantes empleos de esta palabra). En segundo lugar, el portador de esos despojos fue un laico: Galindo Íñiguez, uno de los hijos del primer rey de Pamplona,

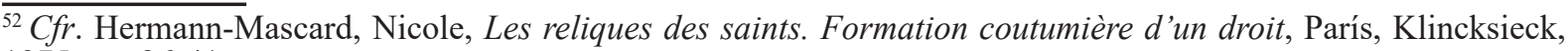
1975 , pp. 26-41.

${ }^{53}$ Ibídem, p. 49.

${ }^{54}$ Epistula ad Wiliesindum... op. cit, \& 9, p. 500: “[...] inde est uel quod non debitum uestrae bonitati dependimus famulatum, uel quod non pio desiderio uestro satisfecimus in transmissione reliquiarum, seu quia non quibuscumque tales tantasque opes comittere duximus ratum".

${ }^{55}$ Ibídem: "[...] domnus Galindo Enniconis ad propia remeans [...] per ipsum uobis praefati martyris reliquias destinauimus. Sed et sancti Aciscli, quas a nobis non postulastis, transmisimus, ut uos sponsionis uestrae uotum feliciter adimplentes eorum beatae memoriae construendo basilicam nobis Deo fauctore propter hanc obedientiam patrocinium illorum occurrat ad ueniam".
} 
Íñigo Íñiguez Arista (al que Eulogio llama “Christicola princeps”). Se trató, por tanto, de un asunto en el que no solo estaban comprometidos altos cargos del clero pamplonés sino la naciente dinastía Arista (a quien, en su búsqueda de recursos propagandísticos para afirmarse en el trono, el tema de las reliquias probablemente no debía serle algo para despreciar). Por último, Eulogio no solo remitió al norte los restos sagrados de san Zoilo sino también los del mártir Acisclo (apelando a las dos figuras más destacadas del santoral local de su época).

Como vemos, el transporte de reliquias entre el norte cristiano y el sur musulmán debía ser algo relativamente habitual a mediados del siglo IX. En ese transporte estaban particularmente interesados ciertos obispos de la época, deseosos de incrementar el prestigio y poder de sus respectivas sedes. Por el contrario, nada se dice de supuestos viajes de las mismas reliquias a fin de escapar de la furia musulmana. Esta observación me parece válida ya que ella contradice un argumento que se convertirá en leiv motif de los relatos de translationes hispanas a partir del siglo XI: el que justifica la posesión de numerosas reliquias en las sedes septentrionales, transportadas desde el sur para evitar su destrucción por parte de los sarracenos. De hecho, si bien Eulogio mencionó que las autoridades islámicas buscaron borrar toda huella de los mártires contemporáneos (a su juicio, como ya vimos, para impedir que se convirtieran en objeto de veneración), parece claro que esa voluntad solo estaba dirigida a eliminar el recuerdo de un rebelde al poder constituido. Por lo demás, el mismo Eulogio nunca manifestó que los musulmanes hubiesen tenido idéntica voluntad destructiva respecto a los restos de los santos cristianos de épocas anteriores ni que se interesaran demasiado por ellos (al punto que él pudo disponer libremente de varias reliquias para cumplir su promesa al obispo de Pamplona y sin que hubiera interposición alguna del poder islámico). Al fin y al cabo, la veneración de las reliquias jamás fue prohibida por los sarracenos. Una prueba de ello la brindó el propio Eulogio en una passio que compusiera cuando se trasladaron los cuerpos de Jorge, Natalia y Aurelio a la abadía de Saint-Germain-des-Près en $858^{56}$. En ella, el hagiógrafo destacó, como rasgo a ser alabado en estos cristianos, el hecho de que, durante sus respectivas vidas, acudían a las iglesias a adorar esos restos sagrados: "visitaban con toda devoción los sepulcros de los mártires" "57; "es costumbre de los fieles cristianos, como todo el mundo sabe, frecuentar las iglesias y peregrinar con humildad de un santo voto a los sepulcros de los venerables mártires" ${ }^{58}$. Nada de esto, cabe advertir, es lo que provocó el posterior martirio de estos personajes (sino el hecho de haber blasfemado contra la religión islámica).

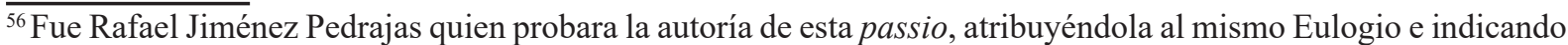
las posibles circunstancias de su producción. A su juicio, se trata de un relato construido tras la redacción de los capítulos del Memoriale sanctorum dedicados a estos mártires, texto que acompañara las reliquias de estos santos en su viaje al norte. Véanse Jiménez Pedrajas, Rafael, "San Eulogio de Córdoba, autor de la Pasión francesa de los mártires mozárabes cordobeses Jorge, Aurelio y Natalia", en Anthologica Annua, 17 (1970), pp. 465-583; y Jiménez Pedrajas, Rafael, "La «Passio Sanctorum Martyrum Georgii Monachi, Aurelii atque Nathaliae», obra original de San Eulogio de Córdoba", en Boletín de la Real Academia de Córdoba, de Ciencias, Bellas Letras y Nobles Artes, 80 (1960), pp. 45-106.

${ }^{57}$ Jiménez Pedrajas, Rafael, "La «Passio Sanctorum..." op. cit., p. 70: "et visitabant [...] loca sanctorum".

${ }^{58}$ Ibídem, p. 94: "Fidelium, ut scitur, mos est ecclesias visitare: et atria venerabilium martyrum, piae devotionis humilitate, requirere".
} 
Precisamente, la translatio de estos últimos personajes fue el segundo suceso de este tenor en el cual probablemente participó Eulogio. A juzgar por el relato de ese viaje - compuesto por un monje de la abadía de Saint-Germain-des-Près, Aimoino, en $871^{59}$-, fueron otros dos miembros de esa congregación, Usuardo y Odilardo, los encargados de esa tarea unos años antes, en $851^{60}$. Deseosos de hallar en Hispania los huesos del mártir san Vicente, esos hermanos vieron frustradas sus expectativas casi de inmediato. Pese a ello, su viaje no fue en vano. Informados de que, en Córdoba, se había desatado una oleada martirial y había numerosos restos de mártires recientes, desviaron su ruta hacia esta última urbe. Tras casi dos meses de estadía (y luego de varias negociaciones), consiguieron los restos de los mencionados Jorge, Aurelio y Natalia (al que acompañaron con el referido relato de la pasión de estos personajes, obra del mismo Eulogio).

Al parecer, varias fueron las personalidades cordobesas involucradas en ese asunto. De hecho, Aimoino se preocupó por subrayar que el traslado de tales mártires no se hizo de manera secreta sino que, todo lo contrario, participaron otros miembros de la jerarquía eclesiástica local. Entre ellos se contaba, con toda probabilidad, la figura de Eulogio. Acerca de este, la narración se limita a señalar que "el muy memorable y sacerdote digno de Dios, Eulogio, que posteriormente también fue entregado a glorioso martirio [...] informó con veraz relato en una composición en la que, como él mismo les refirió a los nuestros, contó muchos detalles" ${ }^{\prime 1}$. Tal composición no sería otra que la aludida, texto que certificó la relevancia de los restos transportados al norte. Por ende, no caben dudas de que Eulogio patrocinó ese traslado, brindando al menos las herramientas discursivas necesarias para ello.

¿Qué fue exactamente lo que Usuardo y Odilardo obtuvieron en Córdoba? Aimoino se detuvo de manera especial en este tema, dando cuenta de las reliquias que se trasladaron a Francia. Según él, los cristianos habían tomado, tras la ejecución de estos mártires, "íntegro el cuerpo del bienaventurado Jorge, en cambio, sin cabeza, el de Aurelio", sepultándolos “en un lugar de la iglesia, debajo del altar" - subrayando una localización que, a primera vista, parece dudosa ${ }^{62}$ - En cuanto a Natalia, según el monje francés, solo se había podido recuperar su cabeza pasados unos días de su muerte -acotación que no coincide con lo indicado por Eulogio, quien había aclarado que "santa Sabigoto fue unida a las cenizas de los Tres

\footnotetext{
${ }^{59}$ Aimoino, De translatione ss. martyrum Georgii monachi, Aurelii et Nathaliae ex urbe Corduba Parisios Patrologia latina 115, cols. 939-960-.

${ }^{60}$ Las características de esta narración y las circunstancias en que se llevó a cabo ese viaje son bien conocidas y han sido comentadas en numerosas ocasiones. Entre los muchos que se han ocupado de este tema, véanse Simonet, Francisco Javier, Historia de los mozárabes de España, Madrid, Turner, 1983, pp. 447-448; Tolan, John, "Reliques et païens..." op. cit.; Tolan, John, Saracens. Islam in the Medieval European Imagination, Nueva York, Columbia University Press, 2002, pp. 100-103; Lara Olmo, Juan Carlos, "El relato del traslado de los santos mártires Jorge, Aurelio y Natalia: un valioso escrito hagiográfico y documental-histórico de mediados del siglo IX", en Hispania sacra, 51 (1999), pp. 55-89 (con una traducción del texto de Aimonio).

${ }^{61}$ Aimoino, De translatione... op. cit., I, 8, col. 953: "Memorabilis et Deo dignus sacerdos Eulogius, qui et ipse postea glorioso donates martyrio Regem Christum consummates miles ovando petivit, veraci relatione plurimis (ut ipse nostris retulit) praetermissis, litteris informavit".

${ }_{62}^{2}$ Ibídem, col. 946: "Et quidem beati Georgii corpus ex integro, Aurelii vero sine capite tollentes in ecclesiae loco sub altari, quemadmodum significamus, sepelierunt".
} 
Santos" $"$ - Por tanto, en el sepulcro en cuestión, "la cabeza de Natalia fue agregada al cuerpo del bienaventurado Aurelio, su cónyuge”, justificando tal aberración (un cuerpo masculino con cabeza femenina) en el sentido de que "puesto que vivieron como un único matrimonio y también fueron compañeros de martirio [...], al morir merecían idéntica veneración en la Tierra..." ${ }^{94}$. Esta salvedad puede vincularse, por otro lado, a la inconclusa referencia de Eulogio en el sentido de que "las cabezas de Jorge y Sabigoto se encuentran..." — que vimos asentada en el Memoriale sanctorum - . De tal manera, como ya anticipamos, es posible que la frase en cuestión no responda a la pluma del mismo Eulogio sino de alguien que, conocedor del relato de Aimoino (¿Ambrosio de Morales?), hubiese advertido este tema, debiendo encontrar una explicación al hecho de que Eulogio nada hubiese dicho sobre esa separación del cadáver de Natalia y la posterior aparición de su cabeza en Peñamelaria.

Como sea, el traslado en cuestión sirvió a Eulogio para confirmar que los mártires por él retratados debían ser considerados auténticos santos y, en tal carácter, sus restos eran anhelados por toda la cristiandad. De hecho, como bien señala Tolan, la llegada de esas reliquias a la Francia carolingia no supuso cambio alguno en la percepción del Islam en el norte de Europa, en la medida en que esos martirios fueron confundidos rápidamente con los del pasado, sin distinguir la acción sarracena en el asunto ${ }^{65}$. En otras palabras, Eulogio vio cumplido su propósito al norte de los Pirineos, donde sus mártires no eran cuestionados ni sus respectivas muertes eran objeto de controversia alguna.

\section{Las reliquias de Eulogio}

Igual que Eulogio reconoció el supuesto carácter divino de los despojos de aquellos mártires que él retrató, otro tanto ocurrió respecto del propio Eulogio una vez ajusticiado por los musulmanes en 859. En efecto, el panegirista y biógrafo del santo, su amigo Paulo Álvaro, también dedicó unas líneas al tema, subrayando la inmediata glorificación de su colega y la necesidad de venerar su cadáver. Según Álvaro, una vez decapitado aquel, su cuerpo fue arrojado por un terraplén hacia el Guadalquivir, momento en el que todos vieron "una nívea paloma de singular blancura, batiendo el aire con sus alas" posarse sobre el mártir. Dado que los asistentes en el lugar trataron de espantarla con gritos y palmas, el ave terminó subiendo

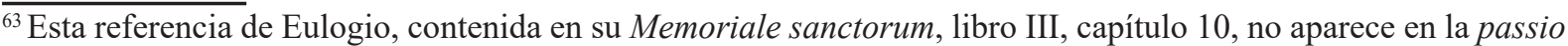
dedicada a estos mártires cordobeses (donde consigna la inhumación de Jorge y Aurelio en Peñamelaria pero nada dice acerca de Natalia-Sabigoto).

${ }^{64}$ Aimoino, De translatione... op. cit., col. 946: “[...] corpori beatum Aurelii caput Nathaliae suae conjugis subrogatum est [...]. Ut quia unius coniugalitatis viventes, necnon et aequalis martyrii socii exstiterant, morientes eiusdem essent merito venerationis in terris [...]".

${ }^{65}$ Tolan, John, "Reliques et païens..." op. cit., p. 47.
} 
hasta una torre vecina "desde donde miraba" el cadáver en cuestión ${ }^{66}$. Por cierto, este tema de la paloma que aparece inmediatamente después de la muerte de un santo también fue un recurso común de la literatura hagiográfica dentro y fuera de la península. En el caso hispano, el antecedente más conocido es, sin dudas, el de santa Eulalia de Mérida, igualmente caracterizada por la aparición de una paloma blanca que salió de la boca de la santa una vez muerta ${ }^{67}$. Como siempre, el ave es símbolo del alma del fallecido, alma perfecta y pura (tal como lo demuestra su color blanco). En el caso de Eulogio, esa verificación de la santidad (y, por ende, del valor de su cuerpo muerto) se repite cuando un soldado, "natural de Écija", la misma noche de tal ajusticiamiento, vio el cadáver del esclesiástico rodeado de unos sacerdotes "de reluciente blancura, portando unas deslumbrantes antorchas" que cantaban salmos. Ambos hechos fueron suficientes para que, al día siguiente, "algunos cristianos curiosos [recuperaran] la cabeza del santo y, al tercero, [hallaran] las reliquias [reliquiae] de su cuerpo", trasladándolas a la misma iglesia de san Zoilo en la que fueron previamente inhumados otros colegas de martirio ${ }^{68}$. La frase es elocuente ya que, por un lado, Álvaro alude a esos restos como "reliquias" (es decir, reconociéndolas como tales), objetos sagrados que fueron encontrados tres días después de la muerte de Eulogio (apelando probablemente a un lapso simbólico por excelencia). De hecho, el mismo autor confirmó esa apreciación al invocar al nuevo mártir en términos de "venerable señor, haznos el favor de igualarnos pues gracias a nuestra solicitud son veneradas tus reliquias y honradas tus exequias [... $]^{\prime 69}$.

Para terminar, Álvaro compuso una alabanza de Eulogio cargada de elementos simbólicos, en la que construyó una de las mejores imágenes de la referida asociación entre reliquias y aromas. Así, señaló que

"he perfumado tus santas cenizas con néctar de flores, que no se consumen
con los ardores del estío ni por la acción del fuego. He ungido tu precioso
cuerpo con la delicada esencia del nardo y con diversas clases de aromas,

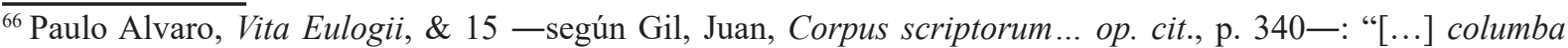
miro candore niuescens, uidentibus omnibus, secans aera pennis super corpus martiris aligerans sedit. Quam omnes missilibus petris hinc inde abigere conantes et nihilominus consistentem repellere non ualentes, manibus uoluerunt ea comminus effugare. Sed illa in circuiti corporis non uolans, sed saliens, super turrem corpori inminentem proprius resedit et ad corpus beatissimi uiri uultum conuertit". Para los antecedentes literarios de la expresión "secans aera pennis" véase Sage, Carleton, Paul Albar of Córdoba: Studies in his Life and Writings, Washington, The Catholic University of America Press, 1943, p. 207, nota 61; y Díaz y Díaz, Pedro Rafael, "Alvaro de Córdoba: «Vida de san Eulogio»", en Florentia Iliberritana, 4-5 (1993-1994), pp. 127-154 —con una traducción del texto-, subrayando la influencia de Draconcio, Eugenio y Sisebuto en este sentido. El tema de la preservación sobrenatural de los restos también está presente, en el texto de Albaro, en el caso de santa Leocricia (compañera de martirio de Eulogio). Al igual que otros muchos, Leocricia fue decapitada y arrojada al río "sed aquis nec submergi potuit, nec celari: erecto enim corpore pergens, mirum omnibus uisum exercuit". Esta mártir entonces fue sacada de las aguas por los cristianos y trasladada a la iglesia de San Ginés (ibídem, \& 16, p. 341).

${ }^{67}$ Fábrega Grau, Ángel, Pasionario hispánico. Tomo II, Madrid-Barcelona, Consejo Superior de Investigaciones Científicas, 1955, p. 76: "Quo facto, ex ore eius, in specie columbe, in conspectu omnium, sancti martyris spiritus migravit ad celum [...]".

${ }^{68}$ Ibídem, \& 15, p. 341 : “Cuius beatissimi caput alio die curiositas Xpianorum redemit, corporis uero reliquias tertio die collegit, et sub umbra beatissimi martyris Zoyli tumulabit".

${ }^{69}$ Ibídem, \& 20, p. 343: "Tu ergo uenerabilis Domine, equiparando nobis redde mercedem, ut quia seruitio nostro tue decorantur reliquie, et ornantur exequie [...]".
} 
combinándolas con amomo, bálsamo y uisamo para que el suavísimo olor de tu santidad, esparcido por todo el siglo, jamás desaparezca"70.

Se trata, como podemos ver, de una clara exaltación de esos restos de Eulogio, interiormente perfumados (como corresponde a todo santo) y doblemente aromatizados por el culto tributado a él.

Las reliquias de Eulogio, al parecer, permanecieron en la mencionada iglesia de San Zoilo hasta 883, año en que fueron sido trasladas (junto con las de su compañera de martirio, Leocricia) a Oviedo. La tradición quiere que el encargado de tal traslado fuese el prebístero Dulcidio - quien encabezó una embajada hacia la España musulmana en 883, según consigna la Crónica albeldense ${ }^{71}$ - Esos restos habrían arribado a Oviedo en enero de 884, en tiempos del obispo Hermenegildo (881-889). Ahora bien, no existen testimonios contemporáneos de este hecho. Se ha sugerido que la cesión de dichos despojos habría estado entre las cláusulas de un tratado firmado entre Alfonso III y Muhammad I — cuyo gestor fue el mismo Dulcidio-. Tal posibilidad (que Ambrosio de Morales fijó de manera contundente y Dozy y Simonet hicieron suya) fue refutada hace años por Cotarelo y Valledor ${ }^{72}$. ¿Qué interés podía tener el monarca asturiano por contar con los restos de un personaje como Eulogio, cuya figura había alterado la situación de la jerarquía cristiana del sur y cuyo culto aún no gozaba de plena aceptación? ¿Por qué proceder al traslado hacia Oviedo de las reliquias de un santo reciente y no de aquellas pertenecientes a uno de mayor arraigo o relevancia histórica? Al fin y al cabo, el mismo Eulogio había remitido al norte restos de santos de tiempos romanos, bien conocidos en toda la península. Por lo demás, la idea de todo este transporte descansa fundamentalmente en un pasaje del Breviario antiguo de Oviedo — que sabemos editado a mediados del siglo XVI pero ignoramos totalmente cuándo se compuso el relato de este traslado en cuestión-. Este texto reconstruye la historia de Dulcidio y un tal Samuel, que lo había ayudado a obtener esos restos (lo cual también contradice la noción de un acuerdo formal entre Alfonso III y su par sarraceno $)^{73}$. No obstante todo esto, los restos de Eulogio sí figuran en el catálogo de reliquias de Oviedo conservado en el ms. 99 de la Biblioteca municipal de Valenciennes - texto que se ha datado tradicionalmente del siglo xi pero que bien puede ser posterior-, en el que

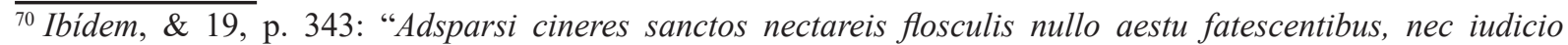
cedentibus i[n]gne. Unxi pretiosum corpus nardo pistico pretioso ac diuerso thimiamatum genere, amomo, balsamo, uisamoque commiscens, ut flagrans sanctitatis tue suauissimus odor difusus, per tota reficiens secula nullo fine tepescat". El término uisamo (en otros autores, bisamo) deriva del árabe wasma o wisama y designa "las hojas de una planta semejante al mirto, cuyo jugo espeso se emplea como tinte para los cabellos o cejas" -González Muñoz, Fernando, Latinidad mozárabe. Estudios sobre el latín de Álvaro de Córdoba, La Coruña, Universidad de La Coruña, 1996, p. 228-. Cfr. Sage, Carleton, Paul Albar... op. cit., p. 213, nota 84.

${ }^{71}$ Crónica albeldense, XV, 13 (edición de Gil Fernández, Juan et al., Crónicas asturianas, Oviedo, Universidad de Oviedo, 1985, p. 181).

${ }^{72}$ Cfr. Cotarello y Valledor, Armando, Historia crítica y documentada de la vida y acciones de Alfonso III el Magno, último rey de Asturias, Madrid, Librería de Victoriano Suárez, 1933, p. 290. Véase de Morales, Ambrosio, Crónica general de España. Tomo VIII, libro XV, Madrid, Oficina de Benito Cano, 1791, cap. 15, pp. 37 y ss.

${ }^{73}$ Flórez, Enrique, España sagrada ... op. cit., p. 467. La inexistencia de ese tratado de paz también fue rechazada en Sánchez-Albornoz, Claudio, "Alfonso III y el particularismo castellano", en Cuadernos de historia de España, 13 (1950), pp. 19-100 (en particular, p. 45), aunque sí admite el traslado de las reliquias de Eulogio y Leocricia.
} 
aparecen tanto dicho personaje como la mencionada Leocricia encabezando la lista de santos cuyas reliquias se encuentran en la basílica de San Salvador de esa ciudad ${ }^{74}$. En síntesis, me inclino a pensar en la elaboración de alguna tradición que - conocedora del viaje de Dulcidiorelacionara la embajada enviada por Alfonso III con la obtención de los despojos del mártir cordobés, tradición que quizás fue formulada en algún momento del siglo x o, mejor aún, a comienzos del XI.

En síntesis, controversia religiosa, crisis social, reivindicación de los valores del pasado, rechazo a la creciente islamización y auténtico sentimiento devocional son, pues, algunos de los valores que se enfrentaron en la Córdoba del siglo Ix en la búsqueda de un nuevo esquema de vida y pensamiento por parte de la comunidad cristiana local. Vocero destacado de esa situación, Eulogio buscó dar a conocer ese complejo circuito de intereses, elaborando un discurso original aunque pleno de contradicciones. En ese marco debe entenderse su caracterización de los mártires de su tiempo y, con ello, de los restos mortales de esos personajes. Oscilantes entre su condición humana y su posible carácter divino, tales mártires no son más que la expresión de las tensiones propias de la época, en un espacio que se debatía entre la resistencia feroz al invasor y la convivencia pacífica con él.

\footnotetext{
${ }_{74}^{7}$ De Bruyne, Donatien, “Le plus ancien catalogue des reliques d'Oviedo", en Analecta bollandiana, 45 (1927), pp. 93-96 (en particular, p. 95).
} 